\title{
DIFFERENTIATION OF CA1 CELL ELEMENTS IN RAT HIPPOCAMPUS ONTOGENESIS
}

\author{
Hana Brichová
}

Institute of Histology and Embryology, $1^{\text {st }}$ Medical Faculty, Charles University, Albertov 4, 12801 Prague 2, Czech Republic e-mail: hana.brichova@1lf.cuni.cz

Received: September 20, 2004

Key words: Hippocampal formation/Neuroepithelium/Neuroblast/Glioblast/Apoptosis/Neuron/Astrocyte/Microglia/Oligodendrocyte/Hypertrophy/Oedema/Phagocytosis/

Development of cell elements of CA1, their interaction in the process of cell differentiation during hippocampal band formation, developed CA1, and changes in the ageing process are discussed.

\section{INTRODUCTION}

Morphofunctional differentiation of neuroepithelial cells of the hippocampal formation was studied in the course of ontogenesis in the male Wistar rat. Histological, immunocytochemical and electronmicroscopical (EM) methods were used.

\section{MATERIAL AND METHODS}

In this study male Wistar albino rats in the period E10 - P1080 were chosen as an experimental group. As controls male rats of P90 were used. For the LM study Nissl's staining, eosin, Griffonia simplicifolia lectin (GSA), antivimentin, anti-GFAP, anti-ß-III-tubulin, anti-OX2 were used. Immunoreactions were visualized with peroxidase. Slices were prepared either from the tissue fixed in $96 \%$ alcohol with $5 \%$ of acetic acid, embedded in D-wax or

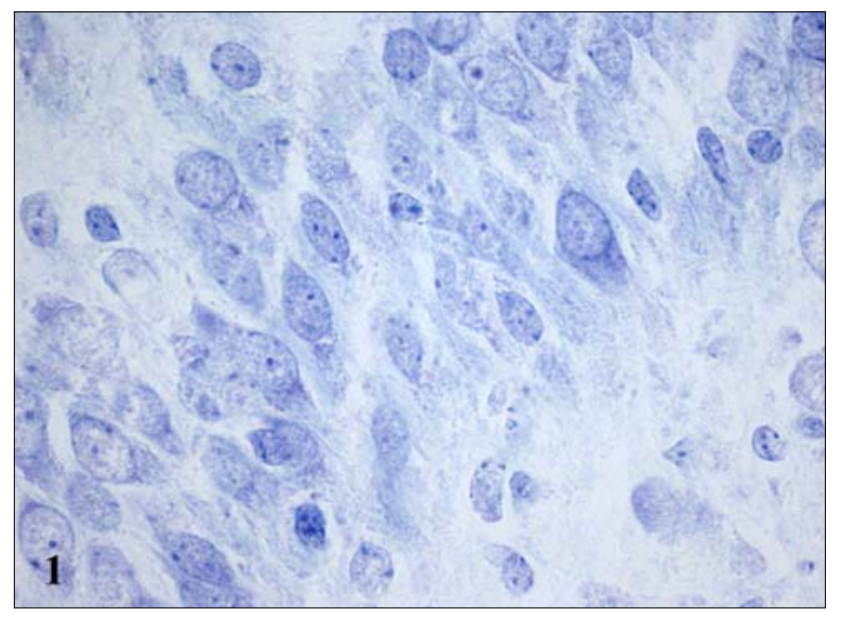

Fig. 1. E19. Hippocampal band was formed above the undifferentiated hippocampal neuroepithelium. Nissl's staining. Obj. magn. x 25 from $4 \%$ paraformaldehyde fixed frozen tissue. Semithin sections were used. For the EM study Karnovsky's fixation, osmication and tissue embedding in Epon 812 were performed.

\section{RESULTS AND DISCUSSION}

At E12, vimentin positive cells and radial glia fibers were confirmed in the ventricular zone. Traces of hippocampal band were found in neuroepithelium of the hippocampal formation on day E14. Early neuroblast cytoplasm still contained low quantity of organelles. At E18, groups of globose microglia cells were localized in the lateral ventricle region in the connection with apoptotic processes. Vimentin positive elements were still present in the stem cell group of hippocampal formation. On day E19, among the OX4 and $\beta$-III-tubulin positive neuroblasts GFAP positive astroblast processes were found in

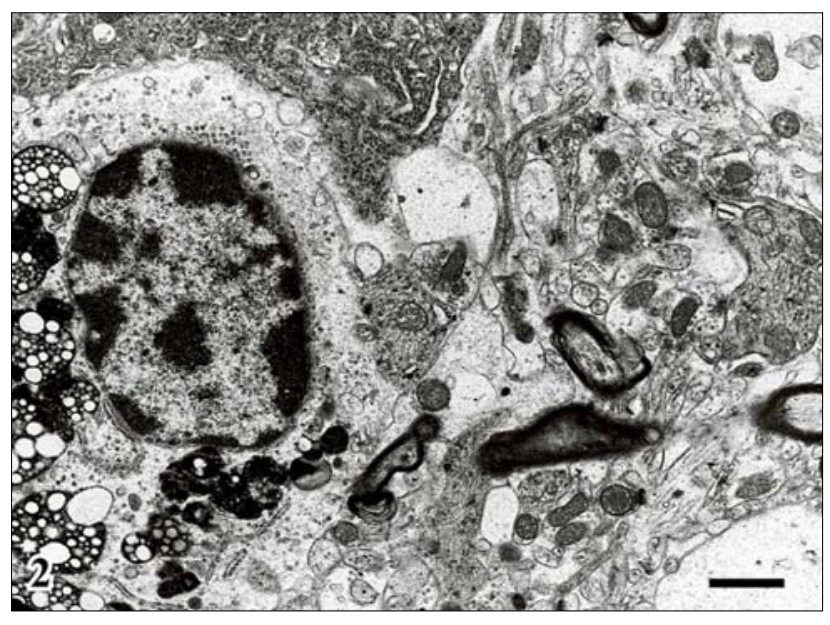

Fig. 2. Cytoplasm of microglia was filled with a high amount of phagocyted material. Hypertrofic and oedematous astrocyte processes were present between aging neurons $\mathrm{P} 1080$. Bar $=1 \mu \mathrm{m}$. 
the hippocampal band. EM observation confirmed these findings. From P6 - P15 B-III-tubulin positive pyramidal neurons and differentiated GFAP positive astrocytes were present in the tissue of CA1. Cell groups showing stem cell features still survived in the hippocampal formation and subependymal layer. At P90, in CA1, there were no differences in the ultrastructure of the neurons and glial elements of hippocampus and cerebral cortex. In the ageing brain increased number of GFAP positive astrocytes, highly developed hypertrophy and oedema of those cells joined to the altered neurons and evident increase in amount of the phagocyting microglia cells, which survived in the tissue, were observed in the CA1 of hippocampus. Proliferating astrocytes were still found. Ultrastructural differences, conditioned by changed cytophysiology in the ageing CA1, were observed in the cytoplasm of all types of nervous tissue cells and blood vessels. Compared with controls, these morphological changes were confirmed by immunocytochemical studies.

In the ageing hippocampus, on the basis of the results presented here, it is believed that an increase in the amount and size of both altered astrocytes and microglia cells, filled with a high amount of phagocyted material, created a barrier between either the nerve cells and synapsis or capillaries and nerve cells. Nerve cell uptake of nu- trients and oxygen was markedly decreased and therefore the metabolism of neurons was lowered. The transport and utilization of proteins, produced by the nerve cells, was decreased or stopped due to the astrocyte processes's oedema and barrier of microglia cells. Nerve cells which didn't have active synaptic contacts and adequate oxygen and nutrients supply were altered and finally died.

\section{CONCLUSION}

The mechanisms which originally differentiated to improve nervous tissue function, failed in the process of ageing.

\section{ACKNOWLEDGEMENT}

This study was supported by the research project MSM111100001

\section{REFERENCE}

1. Brichová H, Šimonová Z, Syková E. (2000) Morphology of aging rat hippocampus. Anat Anz Suppl, 182: 154-5 